\title{
Surgical technique for placement of the Melody valve in a dilated right ventricular outflow tract
}

\author{
Matteo Trezzi, MD, ${ }^{\text {a }}$ Varsha M. Bandisode, MD, ${ }^{b}$ Minoo N. Kavarana, MD, ${ }^{a}$ and Scott M. Bradley, MD, \\ Charleston, SC
}

\author{
From the Divisions of ${ }^{\mathrm{a}}$ Pediatric Cardiac Surgery and ${ }^{\mathrm{b}}$ Pediatric Cardiology, Medical University of South \\ Carolina, Charleston, SC. \\ Disclosures: Authors have nothing to disclose with regard to commercial support. \\ Received for publication May 22, 2017; revisions received July 3, 2017; accepted for publication July 21, 2017; \\ available ahead of print Sept 7, 2017. \\ Address for reprints: Scott M. Bradley, MD, Professor of Surgery, Pediatric Cardiac Surgery, Medical University \\ of South Carolina, CSB 424, 96 Jonathan Lucas St, Charleston, SC 29425 (E-mail: bradlesm@musc.edu). \\ J Thorac Cardiovasc Surg 2018; 155:739-41 \\ $0022-5223 / \$ 36.00$ \\ Copyright (C) 2017 by The American Association for Thoracic Surgery \\ http://dx.doi.org/10.1016/j.jtcvs.2017.07.082
}

Video clip is available online.

Increasing numbers of patients with pulmonary regurgitation are candidates for percutaneous valve placement. The Melody transcatheter pulmonary valve (Medtronic, Minneapolis, Minn) consists of a valved bovine jugular vein mounted within a supporting stent. This stent provides a rigid, cylindrical support for the valve, which results in excellent early competence and a 5-year freedom from explantation of $92 \%$. $^{1}$ The structure of the valve is also optimal for subsequent valve-in-valve replacement. Patients with a dilated outflow tract, including those with a previous transannular patch, are not generally considered as candidates for Melody valve implantation. These patients commonly undergo surgical placement of a bioprosthetic valve. ${ }^{2}$ Bioprosthetic valves have variable durability and do not always provide an acceptable landing site for future valve-in-valve re-replacement. This can be due to angulation of the valve in the outflow tract, as well as to heavy calcification not amenable to dilation. Placement of a Melody valve within a bioprosthetic valve also results in flaring of the Melody stent, which can compromise the competence of the Melody valve.

These considerations led us to pursue an alternative approach to pulmonary valve placement in patients with a dilated outflow tract. The approach involves placement within the outflow tract of a 24-mm GORE-TEX polytetrafluoroethylene graft (W. L. Gore \& Associates, Inc, Flagstaff, Ariz), which then serves as a landing site for a Melody valve placed under direct vision (Figure 1). We

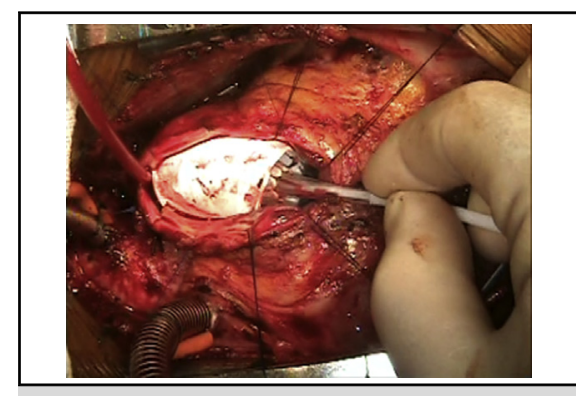

A 24-mm GORE-TEX graft as a landing site for a Melody valve in a dilated outflow tract.

Central Message

A technique is described for placement of a Melody valve in a dilated outflow tract under direct vision. The approach involves inclusion placement of a GORE-TEX graft as a landing site for the valve.

See Editorial Commentaries pages 742 and 744.

describe the technical approach and short-term outcome in 8 patients.

\section{SURGICAL TECHNIQUE}

As shown in Video 1, the operation is performed through a resternotomy with normothermic cardiopulmonary bypass with aortic and right atrial cannulation. Aortic crossclamping is used as needed for concomitant procedures. The right ventricular outflow tract is opened longitudinally. A 24-mm diameter polytetrafluoroethylene tube graft is cut to $3 \mathrm{~cm}$ in length. The graft is sewn into the outflow tract "inclusion style" with running 4-0 Prolene polypropylene suture (Ethicon, Inc, Somerville, NJ). The distal end is sewn to the main pulmonary artery just proximal to the takeoff of the right branch pulmonary artery. The proximal end is then sewn where it falls, generally at the level of the native pulmonary valve, or more proximally in the right ventricular infundibulum. Both the distal and proximal suture lines are left open anteriorly for visualization during stent and valve placement. Under direct vision, the polytetrafluoroethylene graft is "prestented" by placing a Palmaz XL P3110 stent (Cordis, Milpitas, Calif) within the graft and dilating to 24-mm. The goal of presenting is to prevent valve stent fracture. ${ }^{1,3}$ A Melody valve is then placed within 


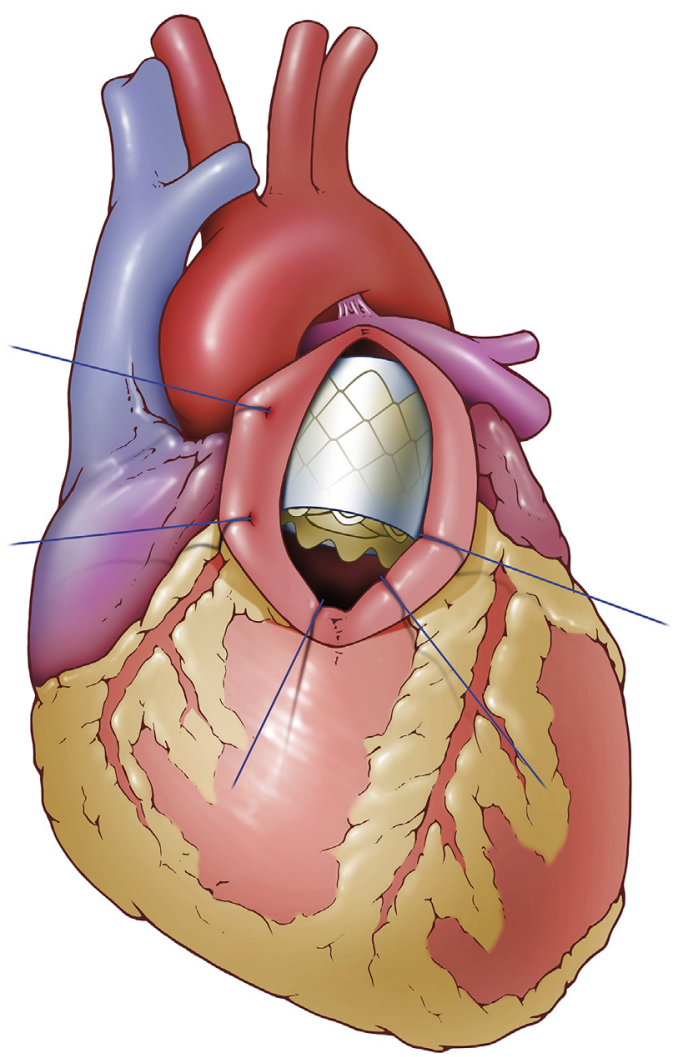

FIGURE 1. Inclusion placement of a 24-mm GORE-TEX polytetrafluoroethylene graft (W. L. Gore \& Associates, Inc, Flagstaff, Ariz) to serve as a landing site for a Melody valve (Medtronic, Minneapolis, Minn) in a dilated right ventricular outflow tract.

the stented polytetrafluoroethylene graft and dilated to an internal diameter of 22-mm. Several balloon inflations are used to ensure complete contact between the Melody valve and the polytetrafluoroethylene graft. The Melody stent is additionally tacked to the proximal end of the graft with several interrupted sutures. The distal and proximal polytetrafluoroethylene graft suture lines are then completed. These suture lines are $360^{\circ}$ to avoid a perigraft leak. Finally, the incision in the outflow tract is closed over the graft, with an additional small patch if needed. Valve function is evaluated by transesophageal echocardiography. Patients receive anticoagulation with aspirin for 6 months.

\section{RESULTS}

This technique has been used in 8 patients at a median age of 13 years (range, 10-53 years) and median weight of $38 \mathrm{~kg}$ (range, 25-67 kg; Table 1). Median cardiopulmonary bypass time for isolated Melody valve placement was 110 minutes (range, 82-125 minutes). Two patients had aortic crossclamping for concomitant procedures. There were no perioperative complications. All patients were discharged from the hospital by postoperative day 4 . Discharge echocardiography showed a median Melody
TABLE 1. Patient diagnoses and procedures

\begin{tabular}{lllc}
\hline Patient & Diagnosis & Previous operations & $\begin{array}{c}\text { Concomitant } \\
\text { procedures }\end{array}$ \\
\hline 1 & PS & Pulmonary TAP & TV repair (DeVega) \\
\hline 2 & TOF & TOF repair with TAP & \\
\hline 3 & TOF & TOF repair & TV repair (ring); \\
& & & cryomaze \\
\hline 5 & TOF & TOF repair with TAP & \\
\hline 6 & PS & Pulmonary TAP & \\
\hline 7 & TOF & TOF repair with TAP & Repair LPA stenosis \\
\hline 8 & TOF & TOF repair with TAP & \\
\hline$P S$, Critical valvular pulmonary stenosis; $T A P$, transannular patch; $T V$, tricuspid valve; \\
$T O F$, tetralogy of Fallot; $L P A$, left pulmonary artery. & \\
\hline
\end{tabular}

valve gradient of $15 \mathrm{~mm} \mathrm{Hg}$ (range, 0-32 $\mathrm{mm} \mathrm{Hg}$ ). Seven patients had no or trivial Melody insufficiency. One patient with mild insufficiency and a gradient of $32 \mathrm{~mm} \mathrm{Hg}$ underwent cardiac catheterization 2 months after surgery. The Melody valve was noted to be slightly narrowed, possibly from recoil. Redilation resulted in no remaining gradient and trivial insufficiency. At a mean follow-up of $26 \pm 10$ months, echocardiography showed stable Melody valve function in all patients, with a median gradient of $15 \mathrm{~mm} \mathrm{Hg}$ (range, 9-18 $\mathrm{mm} \mathrm{Hg}$ ) and no or trivial insufficiency in all cases.

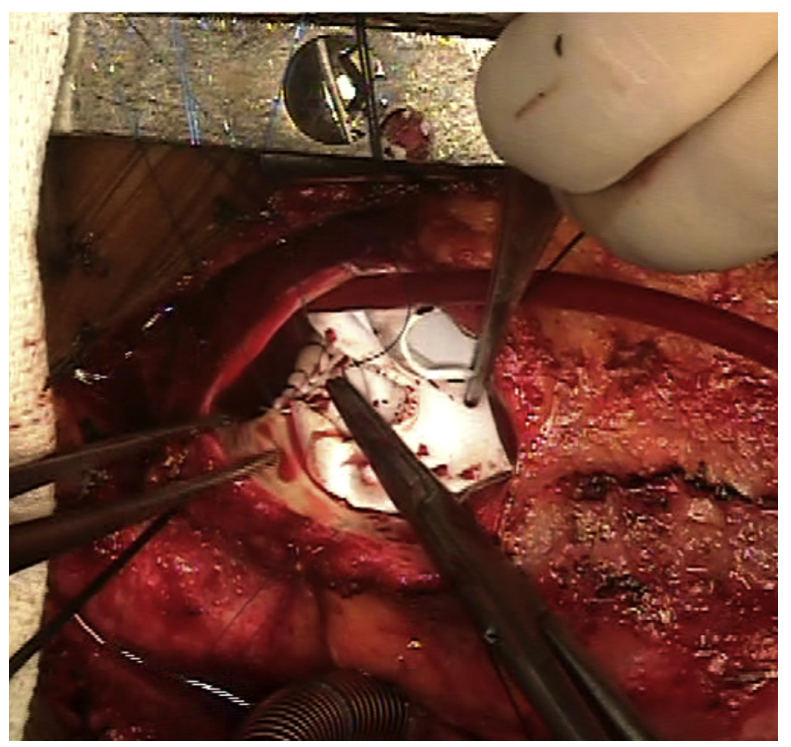

VIDEO 1. The video illustrates the surgical technique of placing a GORETEX polytetrafluoroethylene graft (W. L. Gore \& Associates, Inc, Flagstaff, Ariz) within a dilated right ventricular outflow tract. The graft then serves as a landing site for a Melody valve (Medtronic, Minneapolis, Minn) placed under direct vision. Video available at: http://www. jtcvsonline.org/article/S0022-5223(17)31780-4/fulltext. 


\section{DISCUSSION}

This surgical technique allows placement of a Melody valve in a dilated outflow tract under direct vision. The approach is technically straightforward and has good short-term results. Should these patients require valve re-replacement in the future, we propose that the regular, cylindrical geometry of the stented polytetrafluoroethylene graft will consistently provide an optimal landing site for a transcatheter valve. Another approach to placement of a Melody valve in a dilated outflow tract is external dissection with plication of the outflow tract, followed by perventricular (hybrid) valve placement. ${ }^{4,5}$ Compared with this alternative, our approach requires cardiopulmonary bypass but offers the advantages of avoiding circumferential outflow tract dissection in a redo field and providing a uniform cylindrical site for Melody valve positioning. Comparison of the results of this approach versus other options for pulmonary valve placement requires further experience and follow-up.

\section{References}

1. Cheatham JP, Hellenbrand WE, Zahn EM, Jones TK, Berman DP, Vincent JA, et al. Clinical and hemodynamic outcomes up to 7 years after transcatheter pulmonary valve replacement in the US Melody valve investigational device exemption trial. Circulation. 2015;131:1960-70.

2. Nomoto R, Sleeper LA, Borisuk MJ, Bergerson L, Pigula FA, Emani S, et al. Outcome and performance of bioprosthetic pulmonary valve replacement in patients with congenital heart disease. J Thorac Cardiovasc Surg. 2016;152 1333-42.

3. McElhinney DB, Cheatham JP, Jones TK, Lock JE, Vincent JA, Zahn EM, et al. Stent fracture, valve dysfunction, and right ventricular outflow tract reintervention after transcatheter pulmonary valve implantation: patient-related and procedural risk factors in the US Melody Valve Trial. Circ Cardiovasc Interv. 2011;4:602-14.

4. Travelli FC, Herrington CS, Ing FF. A novel hybrid technique for transcatheter pulmonary valve implantation within a dilated native right ventricular outflow tract. J Thorac Cardiovasc Surg. 2014;148:e145-6.

5. Porras D, Gurvitz M, Marshall AC, Emani SM. Hybrid approach for off-pump pulmonary valve replacement in patients with a dilated right ventricular outflow tract. Ann Thorac Surg. 2015;100:e99-101. 